(c) American Dairy Science Association, 2004.

\title{
Differential Effects of Steroids and Retinoids on Bovine Myelopoiesis in Vitro
}

\author{
V. Van Merris, E. Meyer, L. Duchateau, and C. Burvenich \\ Department of Physiology, Biochemistry and Biometrics, \\ Faculty of Veterinary Medicine, Ghent University, \\ B-9820 Merelbeke, Belgium
}

\section{ABSTRACT}

Pregnancy and parturition are associated with physiological changes caused by steroid hormones. Alterations in number, maturity, and function of polymorphonuclear leukocytes observed in dairy cows at parturition suggest a common causative relationship with steroid hormones. This study was designed to investigate the effects of progesterone, 17- $\beta$-estradiol, and hydrocortisone on the proliferation of bovine progenitor cells. An in vitro culturing system was used, and colonies were scored after $7 \mathrm{~d}$ of incubation. At low concentrations, $17-\beta$-estradiol inhibited proliferation of granulocyte progenitor cells. Hydrocortisone reduced growth of granulocyte and monocyte colonies, whereas myelopoiesis was not altered by progesterone. Furthermore, we studied the effect of retinoids on colony formation of bovine bone marrow cells. All-trans- and 9-cis-retinoic acid stimulated growth of granulocyte colonies and inhibited proliferation of the monocyte lineage. The addition of the 13-cis-isomer also increased numbers of granulocyte colony-forming units. This study indicates that steroid hormones may be responsible for alterations in the bovine hematopoietic profiles observed in circulation during the postpartum period. White blood cells, especially polymorphonuclear leukocytes, which are derived from bone marrow, are an important first line defense against mastitis. Therefore, these effects of steroids might contribute to the increased susceptibility of dairy cows to Escherichia coli mastitis. We furthermore hypothesize that an important role might be attributed to retinoic acid in its regulation of bovine myelopoiesis. Modulation of myelopoiesis in favor of the granulocyte lineage during the acute-phase reaction may be an adaptive mechanism designed to increase the capacity of first-line defense to intramammary infections.

Received: October 8, 2003.

Accepted: November 6, 2003.

Corresponding author: C. Burvenich; e-mail: Christian.Burvenich @UGent.be.
(Key words: steroid hormone, retinoic acid, bone marrow, myelopoiesis)

Abbreviation key: cfu-G = colony-forming unit-granulocyte, $\mathbf{c f u}-\mathbf{G M}=$ colony-forming unit-granulocyte and monocyte, cfu-M = colony-forming unit-monocyte, $\mathbf{c f u -}$ total = colony-forming unit-total myeloid, FBS = fetal bovine serum, IMDM = Iscove's modified Dulbecco's Minimal Essential, PMN = polymorphonuclear leukocytes, $\mathbf{R A R}=$ retinoic acid receptor, $\mathbf{R X R}=$ retinoid $\mathrm{X}$ receptor.

\section{INTRODUCTION}

A significant increase in the susceptibility to infectious diseases in dairy cows occurs around parturition. Incidence of clinical mastitis caused by environmental pathogens, such as Escherichia coli, is highest during the immediate postpartum period (Erskine et al., 1988). During the periparturient period, changes in number, differentiation, maturity, and function of circulating polymorphonuclear leukocytes (PMIN) have been observed (Dosogne et al., 1999; Mehrzad et al., 2002). Several of the altered PMN functions as well as numbers of circulating PMN were found to be related to the severity of experimentally induced Escherichia coli mastitis during early lactation (Heyneman et al., 1990; Van Werven et al., 1997). Efficient functioning of PMN is necessary during the early phase of infection in order to clear the mammary gland from invading pathogens.

Pregnancy and parturition impose important physiological changes in steroid hormones that are produced by the placenta and the adrenal gland (Smith et al., 1973; Convey, 1974). Progesterone is the dominant hormone throughout pregnancy. Progesterone declines precipitously to nearly undetectable concentrations the day before parturition. Total plasma estrogen concentrations are relatively low in early lactation, increase 10 -fold in midgestation, and then remain consistently elevated. One week before parturition, estrogens further increase, rising to peak concentrations on the day of parturition. Concentrations of plasma cortisol increase $3 \mathrm{~d}$ before calving and peak the day after parturition. 
Because hormonal changes are concomitant with observed changes in function, number, differentiation, and maturity of circulating PMN, steroids might be involved in the underlying mechanisms of the abovementioned leukocytic changes. Research mainly has focused on circulating PMN, as they form the first-line defense against infectious diseases. Hoedemaker et al. (1992) provided evidence for the influence of cortisol, estrone, 17- $\beta$-estradiol, and progesterone on bovine PMN function (either stimulatory or inhibitory). In contrast to earlier results (Moreira da Silva et al., 1997), Winters et al. (2003) found no significant changes in PMN oxidative burst activity at physiological or pharmacological concentrations of estrogens. However, Roth et al. (1983) reported that a combination of low concentrations of estradiol with high concentrations of progesterone was associated with a reduced oxidative metabolism and enhanced random migration of PMN. Recently, Hoeben et al. (1999) provided a first indication of the immunosuppressive effect of some metabolites and hormones whose concentrations change dramatically during the periparturient period in bovine. Acetoacetic acid, $\beta$-hydroxybutyric acid, and bovine pregnancy-associated glycoprotein were found to inhibit the colony formation of bovine bone marrow cells.

Besides hormonal fluctuations, important changes in blood vitamin A concentrations take place during the periparturient period of dairy cows. We recently observed a shift in retinoid metabolism during experimentally induced $E$. coli mastitis in the immediate postpartum period, suggesting a key role for the biologically active metabolite all-trans-retinoic acid (Van Merris et al., 2004).

The aim of the present study was to investigate the in vitro effect of steroids whose concentrations change abruptly around parturition on the proliferation of bovine progenitor cells. Furthermore, we studied the involvement of retinoids on myelopoiesis because vitamin A, and especially retinoic acid, is known to modulate the immune response and normal hematopoiesis in humans (Collins, 2002).

\section{MATERIALS AND METHODS}

\section{Isolation of Mononuclear Bone Marrow Cells}

Bovine bone marrow samples were collected from the sternum of adult cows at the abbatoir located at the Ghent University (Melle, Belgium). Before splitting of the carcass, $2 \mathrm{~mL}$ of marrow was aspirated from the third or fourth sternebra (Van Merris et al., 2001b) by means of a Janus needle (Bignell Surgical Instruments Ltd., Arundel, England). Bone marrow samples were transferred on ice into sterile tubes containing Iscove's modified Dulbecco's Minimal Essential Medium
(IMDM) (Gibco BRL, Life Technologies Inc., Gaithersburg, MD) with $584 \mathrm{mg} / \mathrm{L}$ of L-glutamine, supplemented with 10\% fetal bovine serum (FBS) (Gibco BRL) and $100 \mathrm{U} / \mathrm{mL}$ of lithium heparin (Leo Pharmaceutical Product, Zaventem, Belgium).

Bone marrow cells were mixed gently before further processing. Mononuclear bone marrow cells were isolated by gradient centrifugation $(400 \times \mathrm{g}, 20 \mathrm{~min}$, room temperature) of the bone marrow suspension on FicollPaque (Amersham Bioscience, Uppsala, Sweden) with a specific density of $1.077 \mathrm{~g} / \mathrm{mL}$ (Van Merris et al., 2001a). Light density mononuclear cells were harvested from the interface, the cell suspension was washed twice (400 $\times g, 10 \mathrm{~min}$, room temperature) and finally resuspended in IMDM.

\section{Culture of Bovine Bone Marrow Cells}

Bone marrow mononuclear cells were cultured using an in vitro culture assay optimized for the bovine by Van Merris et al. (2001a). The semi-solid culture system for myeloid colonies consisted of $0.9 \%$ high-viscosity methylcellulose (Methocel, Fluka Chemie, Buchs, Switzerland), $30 \%$ of non heat-inactivated FBS, $1 \%$ of deionized bovine serum albumin (BSA fraction V 7.5\%; Sigma Chemical Co., St. Louis, MO), 3\% concanavalin A-stimulated lymphocyte conditioned medium, $10 \mathrm{mM} 2$-mercapto-ethanol (Sigma Chemical Co.), and IMDM supplemented with penicillin-streptomycin and amphotericinB (Sigma Chemical Co.). A volume of $1 \mathrm{~mL}$ of methylcellulose-gel containing $1 \times 10^{5}$ cells was plated out per 35 mm culturing dish (StemCell Technologies, Vancouver, Canada). All cultures were carried out in duplicate. Colonies were scored after a 7 -d incubation at $37^{\circ} \mathrm{C}$ in 95\% relative humidity and under $5 \% \mathrm{CO}_{2}$ in air (Binder $\mathrm{GmbH}$, Tuttlinger, Germany).

\section{Experimental Procedures}

Progesterone (4-pregnene-3,20-dione), 17- $\beta$-estradiol (1,3,5[10]-estratriene-3,17-b-diol), hydrocortisone (17hydrocorticosterone 21-acetate), all-trans-, 9-cis-, and 13-cis- retinoic acid were purchased (Sigma Chemical Co.). Appropriate stock solutions were prepared in ethanol and further diluted in IMDM. Final ethanol concentration in the culture medium was $0.005 \%$. The solvent effect of ethanol on colony formation was investigated before beginning the experiment. Number and type of colonies were not affected by increasing the concentration of ethanol to a final concentration of $0.005 \%$. Because retinoids degrade upon exposure to light, all experiments were carried out under dim yellow light. The previously described culture medium was supplemented randomly with progesterone (final concentra- 
Table 1. Effect of the highest tested concentration of progesterone $(500 \mathrm{ng} / \mathrm{mL}), 17$ - $\beta$-estradiol $(10 \mathrm{ng} / \mathrm{mL})$, hydrocortisone $(100 \mathrm{ng} / \mathrm{mL})$, and all-trans- (100 ng/mL atRA), 9-cis- (100 ng/mL 9cisRA), and 13cis-retinoic acid (100 ng/mL 13cisRA) tested on total myeloid colonyformation (cfu-total), colony-forming unit-granulocyte (cfu-G), and colony-forming unit-monocyte (cfu-M) ${ }^{1}$.

\begin{tabular}{lccc}
\hline Treatment & cfu-total & cfu-G & cfu-M \\
\hline $\begin{array}{c}500 \mathrm{ng} / \mathrm{mL} \\
\text { progesterone }\end{array}$ & $102.05 \pm 7.00$ & $100.62 \pm 11.40$ & $110.14 \pm 20.01$ \\
$\begin{array}{c}10 \mathrm{ng} / \mathrm{mL} \\
\text { estradiol }\end{array}$ & $64.81 \pm 9.26$ & $58.76 \pm 11.20$ & $93.32 \pm 21.72$ \\
$100 \mathrm{ng} / \mathrm{mL}$ & $68.45 \pm 6.07$ & $70.70 \pm 6.59$ & $57.99 \pm 5.42$ \\
$\begin{array}{c}\text { hydrocortisone } \\
100 \mathrm{ng} / \mathrm{mL}\end{array}$ & $123.45 \pm 6.44$ & $134.89 \pm 5.93$ & $70.79 \pm 11.97$ \\
$\begin{array}{l}\text { atRA } \\
100 \mathrm{ng} / \mathrm{mL}\end{array}$ & $130.62 \pm 6.75$ & $143.46 \pm 6.91$ & $72.98 \pm 9.98$ \\
$\begin{array}{c}\text { 9cisRA } \\
100 \mathrm{ng} / \mathrm{mL}\end{array}$ & $119.31 \pm 5.56$ & $127.43 \pm 7.09$ & $83.16 \pm 21.05$ \\
$13 \mathrm{cisRA}$ & & & \\
\hline
\end{tabular}

${ }^{1}$ Results are means \pm standard error of the mean of bone marrow mononuclear cell populations isolated from 6 cows and are expressed as cloning-efficiency index.

tion $5,50,100,250$, or $500 \mathrm{ng} / \mathrm{mL}$ ), 17 - $\beta$-estradiol (final concentration $0.01,0.1,1,5$, or $10 \mathrm{ng} / \mathrm{mL}$ ), hydrocortisone (final concentration $5,10,25,50$, or $100 \mathrm{ng} / \mathrm{mL}$ ), or with all-trans-, 9-cis-, or 13-cis-retinoic acid (final concentration $1,5,10,50$, or $100 \mathrm{ng} / \mathrm{mL}$ ). Culture wells were thus exposed to one steroid or retinoid at a time. Methylcellulose-based cultures without the addition of steroids or retinoids were used as controls.

\section{Colony Scoring}

Colony formation was evaluated by a single person using gridded scoring dishes (StemCell Technologies, Vancouver, Canada). Colony types were clearly discernible, based on their typical morphological characteristics. Colony-forming unit-granulocyte and monocyte (cfu-GM) were mixed granulocyte and monocyte colonies containing $>50$ cells with a typical dense center and very widespread growth pattern away from the dense center of the colony. Colony-forming unit-granulocyte (cfu-G) consisted of clusters of $>40$ spherical granulated cells with a very dense circular structure. Colony-forming unit-monocyte (cfu-M) were clusters of $>20$ larger brownish cells that were less densely organized compared with cfu-G. Total myeloid colony formation (cfu-total) was the sum of cfu-GM, cfu-G, and cfu$M$. The mixed myeloid and erythroid colony type did not grow under the experimental conditions reported herein.

Colony formation in each assay was expressed as cloning efficiency, which was the number of colonies per 100 cells in culture. Because $1 \times 10^{5}$ mononuclear bone marrow cells were plated out per well, cloning efficiency of the culture equaled the number of colonies counted in a well, divided by 1000 . The cloning efficiency of the cultures incubated without any steroid or retinoid equaled the number of colonies per 100 untreated cells. This cloning efficiency was further used to express the effect of steroid and retinoid treatment, respectively, compared to the control culture, in terms of cloning efficiency index. Cloning efficiency index was the cloning efficiency of the treated cells divided by the cloning efficiency of the untreated cells multiplied by 100 .

\section{Statistical Analyses}

The effects of steroids (progesterone, 17- $\beta$-estradiol, and hydrocortisone) and retinoids (all-trans-, 9-cis-, and 13-cis-retinoic acid) on cfu-G, cfu-M, and cfu-total were evaluated in a mixed model with cow as random effect and concentration as a categorical fixed effect using the mixed model procedure of SAS (SAS Inst. Inc., Cary, NC). Concentrations were compared pairwise by Tukey's multiple comparisons technique with a global error rate of $5 \%$.

\section{RESULTS}

\section{Cloning Efficiency of Control Cultures}

Mean cloning efficiencies of controls were $0.128 \pm$ 0.016 for cfu-total, $0.105 \pm 0.011$ for cfu-G, and $0.022 \pm$ 0.006 for cfu-M $(n=6)$. The cloning efficiency indices of the highest concentration of each steroid and retinoid tested on cfu-total, cfu-G, and cfu-M are summarized in Table 1. The number of cfu-GM was too low to draw any conclusion.

\section{Effect of Steroids in Culture}

Growth of cfu-G and cfu-M were not altered by progesterone (Figure 1A). Increasing concentrations of 17- $\beta$ estradiol inhibited the growth of bovine mononuclear bone marrow cells. Total myeloid colony formation (cfutotal) was reduced $(P<0.0001)$ at concentrations of 1 , 5 , and $10 \mathrm{ng} / \mathrm{mL}$ compared with the control. Inhibitory action of 17- $\beta$-estradiol was mainly due to the inhibition of cfu-G. A decrease $(P<0.01)$ in number of cfu-G was detected at a concentration of $0.1 \mathrm{ng} / \mathrm{mL}$. At higher concentrations, the number of cfu-G further decreased $(P<0.0001)$. The number of cfu-M was not significantly affected by $17-\beta$-estradiol (Figure 1B).

Hydrocortisone showed inhibitory effects on growth of cfu-total, cfu-G, and cfu-M. Total myeloid colony formation (cfu-total) was inhibited $(P<0.0001)$ at concentrations of hydrocortisone ranging from 10 to $100 \mathrm{ng} / \mathrm{mL}$ compared to the control. Growth of cfu-G was reduced ( $P$ $<0.001$ ) by hydrocortisone at concentrations as low as 

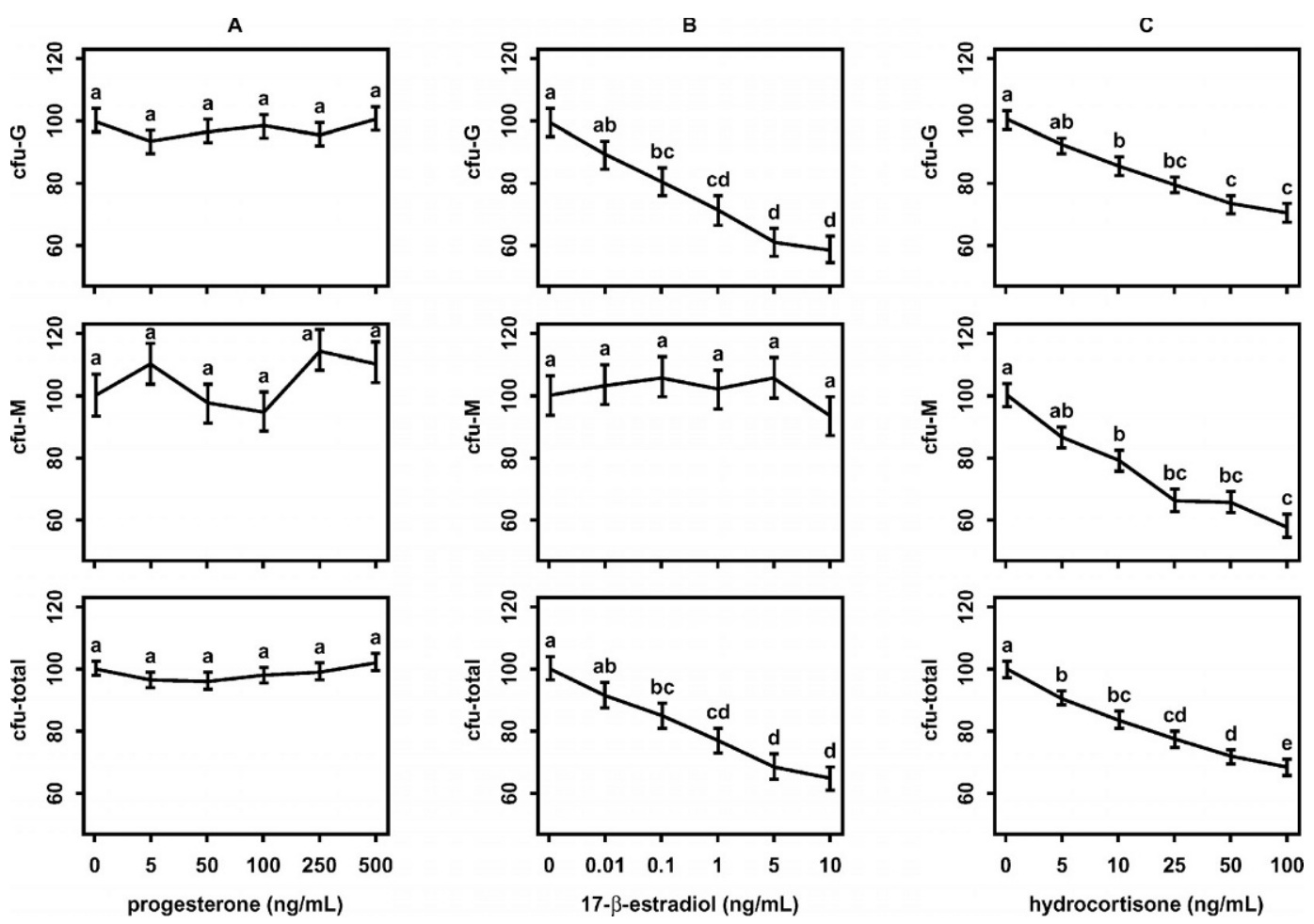

Figure 1. Effect of different concentrations of progesterone (panel A), 17- $\beta$-estradiol (panel B), and hydrocortisone (panel C) on total myeloid colony-formation (cfu-total), colony-forming unit-granulocyte (cfu-G), and colony-forming unit-monocyte (cfu-M). Results are means of bone marrow mononuclear cell populations isolated from 6 cows and are expressed as a cloning-efficiency index. Error bars represent standard errors of the mean. Means with uncommon letters differ (Tukey-Kramer pairwise comparisons with a global error rate of 5\%) from each other.

$10 \mathrm{ng} / \mathrm{mL}$. Growth was further inhibited $(P<0.0001)$ at concentrations of 25,50 , and $100 \mathrm{ng} / \mathrm{mL}$. The inhibitory effect of hydrocortisone on cfu-M paralleled effects of hydrocortisone on cfu-G (Figure 1C). Number of cfuM decreased $(P<0.01)$ in the presence of $10 \mathrm{ng} / \mathrm{mL}$ hydrocortisone and at higher concentrations $(P<$ 0.0001).

\section{Effect of Retinoids in Culture}

All-trans-retinoic acid stimulated cfu-total. Numbers of cfu-total increased $(P<0.0001)$ in the presence of 10 $\mathrm{ng} / \mathrm{mL}$ of all-trans-retinoic acid, with a maximal increase at $100 \mathrm{ng} / \mathrm{mL}$. Differential scoring of the myeloid colonies revealed that this increase resulted from a stimulation of cfu-G $(P<0.0001)$. All-trans-retinoic acid exerted an inhibitory action on cfu-M. Numbers of cfu$\mathrm{M}$ were reduced $(P<0.01)$ at $10 \mathrm{ng} / \mathrm{mL}$ and further decreased $(P<0.001)$ at higher concentrations (Figure $2 \mathrm{~A}$ ).

The effects of 9-cis-retinoic acid on bovine myelopoiesis were identical to those described for all-transretinoic acid. Total myeloid colony formation (cfu-total) was increased $(P<0.0001)$ in the presence of the 9 -cis isomer, starting at a concentration of $10 \mathrm{ng} / \mathrm{mL}$. The stimulatory effect of 9-cis-retinoic acid on cfu-G was more pronounced than the effect induced by all-transretinoic acid. Growth of cfu-M was inhibited at concentrations of $10(P<0.01), 50$, and $100 \mathrm{ng} / \mathrm{mL}(P<0.001)$ (Figure 2B).

In the presence of 13-cis-retinoic acid, the number of cfu-total increased $(P<0.0001$ only at a concentration of $100 \mathrm{ng} / \mathrm{mL}$ ), with lower concentrations having no effect. The stimulatory action of 13-cis-retinoic acid on cfu-total was due to its positive effect on cfu-G at the highest concentration $(P<0.0001)$. Number of cfu-M was not altered by incubation of bone marrow cells with 13-cis-retinoic acid (Figure 2C).

\section{DISCUSSION}

Steroid receptors belong to the nuclear receptor family, which includes 2 major groups based on their ligand binding and the DNA binding domain. These include: (1) receptors for estrogen, progesterone, androgens, gluco- and mineralocorticosteroids, and (2) thyroid-retinoid-vitamin D receptors activated by thyroid hormone, retinoic acids, and vitamin D3, respectively (Kumar and 



Figure 2. Effect of different concentrations of all-trans- (atRA; panel A), 9-cis- (9cisRA; panel B), and 13-cis-retinoic acid (13cisRA; panel C) on total myeloid colony-formation (cfu-total), colony-forming unit-granulocyte (cfu-G), and colony-forming unit-monocyte (cfu-M). Results are means of bone marrow mononuclear cell populations isolated from 6 cows and expressed as a cloning-efficiency index. Error bars represent standard errors of the mean. Means with uncommon letters differ (Tukey-Kramer pairwise comparisons with a global error rate of 5\%) from each other.

Thompson, 1999). Ligands of these receptors mediate pleiotropic cellular processes involved in metabolism, immunity, cellular proliferation, and differentiation.

Our study investigated the effect of steroids, whose concentrations change abruptly at parturition, on the proliferation of myeloid bone-marrow cells in vitro. Furthermore, the involvement of 3 retinoic acid isomers, the biologically active forms of vitamin $\mathrm{A}$, in bovine myelopoiesis was assessed. In the current study, 17- $\beta$ estradiol and hydrocortisone induced inhibitory effects on the proliferation of bovine myeloid bone-marrow cells (cfu-total) at physiological concentrations likely observed at parturition. Very low $17-\beta$-estradiol concentrations $(0.1 \mathrm{ng} / \mathrm{mL})$ decreased the in vitro growth of granulocyte colonies (cfu-G). Plasma concentrations of estrogens range from $0.02 \mathrm{ng} / \mathrm{mL}$ in early gestation to $0.3 \mathrm{ng} / \mathrm{mL}$ during mid- and late pregnancy, and peak between 4 and $8 \mathrm{ng} / \mathrm{mL}$ at calving (Chew et al., 1977). Hydrocortisone inhibited the growth of myeloid progenitors (cfu-G and cfu-M) at a concentration of $10 \mathrm{ng} / \mathrm{mL}$. Physiological concentrations of glucocorticoids in the bovine vary between 4 to $10 \mathrm{ng} / \mathrm{mL}$ and rise to $30 \mathrm{ng} /$ $\mathrm{mL}$ shortly after parturition (Smith et al., 1973). In our study, supraphysiological or physiological concentrations of progesterone neither stimulated nor inhibited bovine myelopoiesis.
A comparative study examining the influence of steroids on bovine bone-marrow cells is limited (Hoeben et al., 1999). Hoeben et al. reported similar inhibitory effects of hydrocortisone on bovine myelopoiesis. Intravenous injection of glucocorticoids in the bovine induces the release of immature myeloid cells from bone marrow into the bloodstream, resulting in more circulating PMN. This resulting leukocytosis is short lived and rapidly followed by leukopenia (Paape et al., 1973). Based on our results, we hypothesize that this might be due to the inhibitory effect of cortisol on the bone marrow progenitor cells. Hydrocortisone strongly inhibited the myelopoiesis in vitro at physiological concentrations. Our observed negative effects of hydrocortisone on bovine bone marrow were similar to those described in mice (Metcalf, 1969) and in humans (Bagby et al., 1980). Treatment of mice with glucocorticoids decreased plasma colony-stimulating factor activity and decreased numbers of cfu-GM (Metcalf, 1969). However, Barr et al. (1983) reported that hydrocortisone exhibited a dose-dependent effect on cfu-GM proliferation in vitro (i.e., enhancement at low concentrations and inhibition at high concentrations). In contrast, more recent studies demonstrated increased numbers of granulocytes not only in circulation, but also in the bone marrow, indicating that myelopoiesis is enhanced 
by in vivo administration of hydrocortisone (Maruyama et al., 1999; Laakko and Fraker, 2002).

The role of estrogens on hematopoietic progenitor cells is well studied. Early results obtained in mice indicated an inhibitory effect of physiological doses of estrogens on several hematopoietic lineages, including granulopoiesis and thrombocytopoiesis (Fried et al., 1974). It was initially thought that the in vivo suppression of hematopoiesis was secondary to replacement of the bone-marrow cavity by new bone because estrogens induce osteosclerosis (Morse et al., 1974). However, Perry et al. (2000) showed that the effects of estrogens on murine hematopoiesis preceded those on bone formation, thus providing evidence for a primary action of the hormone on the hematopoietic marrow. Estrogens were shown to exert their effect indirectly by acting on stromal cells of bone marrow, expressing the estrogen receptor- $\alpha$ (Smithson et al., 1995). Nonhematopoietic elements (e.g., epithelial cells, macrophages, and dendritic cells) are important regulators of hematopoiesis through their release of cytokines. It is possible that the estrogen receptor- $\alpha$ may regulate the production and (or) secretion of cytokines required for hematopoietic cell development. Recently, Thurmond et al. (2000) suggested that the responsiveness of progenitor cells to estrogens in mice was mediated by estrogen receptor$\alpha$ on hematopoietic cells. Although the precise mechanism is unclear, effects of estrogens through estrogen receptor- $\alpha$ on hematopoietic cells seem to induce a blockade of the transition from less mature to more mature progenitor cells.

Our results for the effect of progesterone on bovine myelopoiesis are in agreement with others, where progesterone did not affect progenitor growth in both rats (Benayahu et al., 2000) and humans (Barr et al., 1983). In contrast, progesterone reportedly inhibited proliferation of human cfu-GM cultured in methylcellulose (Smith et al., 1986). Although progesterone alone had no effect in this culture assay, progesterone can enhance the inhibitory effects of estrogen colony formation in mice (Medina and Kincade, 1994).

We could demonstrate that all-trans- and 9-cis-retinoic acid exerted similar effects on total myeloid colony growth (stimulatory), cfu-G (stimulatory), and cfu-M (inhibitory), respectively. The 9-cis analogue enhanced more cfu-G than did all-trans-retinoic acid. 13-cis-Retinoic acid also increased the number of cfu-G. The 13-cis isomer, however, was only effective at a 10 -fold higher concentration than its stereoisomers. Our reported differential effect of all-trans-retinoic acid in semi-solid cultures of bovine myelopoiesis confirm studies performed in humans (Gratas et al., 1993; Van Bockstaele et al., 1993). Enhancement of granulocyte lineage mediated by all-trans-retinoic acid is associated with de- creased production of monocyte, erythroid, and mixed granulocyte/monocyte colonies (reviewed by Collins, 2002).

Serum concentrations of all-trans- and 13-cis-retinoic acid remain stable around parturition in dairy cows (Goff et al., 2002) but are affected by the acute-phase reaction during $E$. coli mastitis (Van Merris et al., 2004). During acute coliform mastitis, an increase of all-trans-retinoic acid is mirrored by decreased 13-cisretinoic acid concentrations, suggesting that a transient bio-activation occurs in the retinoid metabolism. Significant modifications in the activity of retinoid dehydrogenases and isomerases may facilitate the production of all-trans-retinoic acid during infection. It is known that all-trans- and 9-cis-retinoic acids are transcriptionally more active than 13-cis-retinoic acid (Blaner, 2001). Effectiveness of all-trans-retinoic acid on bovine granulopoiesis at lower concentrations than 13-cis-retinoic acid was reported for human bone marrow cultures (Van Bockstaele et al., 1993). Retinoic acid signals are transduced by 2 specific nuclear receptors, the retinoic acid receptor (RAR) and the retinoid $\mathrm{X}$ receptor (RXR) (Petcovich et al., 1987), each comprising subtypes $(\alpha, \beta$, and $\gamma)$, with various isoforms of each subtype. The natural ligands for the RAR are all-trans, 9-cis-, and 13-cis-retinoic acid, whereas RXR is solely activated by 9 -cis-retinoic acid. Most of the effects of retinoic acids are mediated by RAR/RXR heterodimers. The ligand-receptor complexes act as inducible transcription regulators of several genes by binding to specific retinoic acid response elements, with activation or silencing of target genes as a result. The abundant presence of retinoic acid receptors in human granulocyte precursor cells has further stressed the implication of retinoic acid in the differentiation of mature PMN (Chomienne et al., 1990). Retinoic acid regulates the rate of cellular differentiation and apoptosis in bone marrow, depending on the retinoic acid receptor subtype (Mehta et al., 1996). Activation of RAR induces the genes linked with cellular differentiation, whereas activation of RXR induces genes linked with apoptosis. Kastner et al. (2001) recently unraveled the in vivo mechanisms of RAR $\alpha$ as a key mediator for the effects of retinoids on granulopoiesis in rats. Apparently, the receptor can bidirectionally modulate granulopoiesis as a differentiation factor when liganded to retinoic acid or as an inhibitor in the absence of the ligand.

\section{CONCLUSIONS}

From the current study, we suggest that $17-\beta$-estradiol and hydrocortisone may be responsible for physiological alterations in the bovine hematopoietic profiles observed in circulation after parturition. Concentra- 
tions of 17- $\beta$-estradiol inhibited the growth of myeloid colonies and decreased the number of cfu-G. The myeloid pathway also was inhibited by hydrocortisone. Hydrocortisone decreased numbers of cfu-G and cfu-M. The inhibitory effects of 17 - $\beta$-estradiol and hydrocortisone on bovine progenitor cells might contribute to the increased susceptibility of high-milk-producing dairy cattle to $E$. coli mastitis shortly after parturition.

We hypothesize that an important role can be attributed to retinoic acid in the regulation of bovine myelopoiesis because we previously demonstrated a shift in retinoid metabolism to occur during acute $E$. coli mastitis (Van Merris et al., 2004). During the acute-phase reaction, metabolism preferentially results in the production of all-trans-retinoic acid. In the current study, all-trans- and 9-cis-retinoic acid stimulated cfu-G and inhibited cfu-M. This modulation of the myelopoiesis in favor of the granulocyte lineage during the acutephase reaction may be an adaptive mechanism designed to increase the capacity of the first-line defense in response to intramammary infections.

\section{ACKNOWLEDGMENTS}

The authors thank Marc Lenjou (Laboratory for Experimental Haematology, Antwerp University) for his excellent technical advice. V. Van Merris is supported by the Flemish Institute for the Encouragement of Research in the Industry (IWT-Grant No. SB/993161).

\section{REFERENCES}

Bagby, G. C., J. D. Gabourel, and J. W. Linman. 1980. Glucocorticoid therapy in the pre-leukemia syndrome (hemopoietic dysplasia). Ann. Int. Med. 92:55-58.

Barr, R. D., M. Koekebakker, and R. A. Milner. 1983. Hydrocortisone-a possible physiological regulator of human granulopoiesis. Scand. J. Haematol. 31:31-38.

Benayahu, D., I. Shur, and S. Ben-Eliyahu. 2000. Hormonal changes affect the bone and bone marrow cells in a rat model. J. Cell. Biochem. 79:407-415.

Blaner, W. S. 2001. Cellular metabolism and actions of 13-cis-retinoic acid. J. Am. Acad. Dermatol. 45:S129-S135.

Chew, B. P., H. F. Keller, R. E. Erb, and P. V. Malvern. 1977. Periparturient concentrations of prolactin, progesterone, and estrogens in blood plasma of cows retaining and not retaining fetal membranes. J. Anim. Sci. 44:1055-1060.

Chomienne, C., P. Ballerini, N. Balitrand, M. Huang, I. Krawice, S. Castaigne, P. Fenaux, P. Tiollais, A. Dejean, L. Degos, and H. De Thé. 1990. The retinoic acid receptor alpha is rearranged in RA-sensitive promyelocytic leukemias. Leukemia 4:802-807.

Collins, S. J. 2002. The role of retinoids and retinoic acid receptors in normal hematopoiesis. Leukemia 16:1896-1905.

Convey, E. M. 1974. Serum hormone concentrations in ruminants during mammary growth, lactogenesis, and lactation: A review. J. Dairy Sci. 57:905-917.

Dosogne, H., C. Burvenich, A. E. Freeman, M. E. J. Kehrli, J. Detilleux, J. Sulón, J.-F. Beckers, and D. Hoeben. 1999. Pregnancyassociated glycoprotein and decreased polymorphonuclear leukocyte function in early post-partum dairy cows. Vet. Immunol. Immunopathol. 67:47-54.
Erskine, R. J., R. J. Eberhart, L. J. Hutchinson, S. B. Spencer, and B. S. Campbell. 1988. Incidence and types of clinical mastitis in dairy herds with high and low somatic cell counts. J. Am. Vet. Res. 192:761-765.

Fried, W., T. Tichler, I. Dennenberg, J. Barone, and F. Wang. 1974. Effects of estrogens on hematopoietic stem cells and on hematopoiesis of mice. J. Lab. Clin. Med. 83:807-815.

Goff, J. P., K. Kimura, and R. L. Horst. 2002. Effect of mastectomy on milk fever, energy, and vitamins $\mathrm{A}, \mathrm{E}$, and $\beta$-carotene status at parturition. J. Dairy Sci. 85:1427-1436.

Gratas, C., M. L. Menot, C. Dresch, and C. Chomienne. 1993. Retinoic acid supports granulocyte but not erythroid differentiation of myeloid progenitors in normal bone marrow cells. Leukemia 7:1156-1162.

Heyneman, R., C. Burvenich, and R. Vercauteren. 1990. Interaction between the respiratory burst activity of neutrophil leukocytes and experimentally induced Escherichia coli mastitis in cows. J. Dairy Sci. 73:985-994.

Hoeben, D., C. Burvenich, A.-M. Massart-Leën, M. Lenjou, G. Nijs, D. Van Bockstaele, and J.-F. Beckers. 1999. In vitro effect of ketone bodies, glucocorticosteroids and bovine pregnancy-associated glycoprotein on cultures of bone marrow progenitor cells of cows and calves. Vet. Immunol. Immunopathol. 68:229-240.

Hoedemaker, M., L. A. Lund, and W. C. Wagner. 1992. Influence of arachidonic-acid metabolites and steroids on function of bovine polymorphonuclear neutrophils. Vet. Res. 53:1534-1539.

Kastner, P., H. J. Lawrence, C. Waltzinger, N. B. Ghyselinck, P. Chambon, and S. Chan. 2001. Positive and negative regulation of granulopoiesis by endogenous RAR $\alpha$. Blood 97:1314-1320.

Kumar, R., and E. B. Thompson. 1999. The structure of the nuclear hormone receptors. Steroids 64:310-319.

Laakko, T., and P. Fraker. 2002. Rapid changes in lymphopoietic and granulopoietic compartments of the marrow caused by stress levels and corticosterone. Immunology 105:111-119.

Maruyama, S., M. Minagawa, T. Shimizu, H. Oya, S. Yamamoto, N. Musha, W. Abo, A. Weerasinghe, K. Hatakeyama, and T. Abo. 1999. Administration of glucocorticosteroids markedly increases the numbers of granulocytes and extrathymic $\mathrm{T}$ cells in the bone marrow. Cell. Immunol. 194:28-35.

Medina, K. L., and P. W. Kincade. 1994. Pregnancy-related steroids are potential negative regulators of B lymphopoiesis. Proc. Natl. Acad. Sci. USA 91:5382-5386.

Mehrzad, J., L. Duchateau, S. Pyrl, and C. Burvenich. 2002. Blood and milk neutrophil chemiluminescence and viability in primiparous and pluriparous cows during late pregnancy, around parturition and early lactation. J. Dairy Sci. 85:3268-3276.

Mehta, K., T. McQueen, N. Neamati, S. Collins, and M. Andreeff. 1996. Activation of retinoid receptors $\operatorname{RAR} \alpha$ and $\operatorname{RXR} \alpha$ induces differentiation and apoptosis, respectively, in HL-60 cells. Cell Growth Differ. 7:179-186.

Metcalf, D. 1969. Cortisone action on serum colony-stimulating factor and bone marrow in vitro colony-forming cells. Proc. Soc. Exp. Biol. Med. 132:319-324.

Moreira da Silva, F., C. Burvenich, A.-M. Massart-Leën, and F. F. Russell-Pinto. 1997. Effect of some reproduction hormones on the oxydative burst of bovine neutrophils. Flem. Vet. J. 66:297-314.

Morse, B. S., D. Giuliani, M. Soremekun, S. DiFino, and E. R. Giuliani. 1974. Adaptation of hematopoietic tissue resulting from estrogene-induced osteosclerosis in mice. Cell Tissue Kinet. 7:113-123.

Paape, M. J., W. D. Schultze, and R. H. Miller. 1973. Leukocytic response to adrenocorticotropic hormone as influenced by the infectious history of the mammary gland. J. Dairy Sci. 56:733737.

Perry, M. J., A. Samuels, D. Bird, and J. H. Tobias. 2000. Effects on high-dose estrogen in murine hematopoietic bone marrow precede those on osteogenesis. Am. J. Physiol. Endocrinol. Metab. 279:E1159-E1165.

Petcovich, M., J. B. Nigel, A. Krust, and P. Chambon. 1987. A human retinoic acid receptor which belongs to the family of nuclear receptors. Nature 330:444-450.

Roth, J. A., M. L. Kaeberle, L. A. Appell, and R. F. Nachreiner. 1983. Association of increased 17- $\beta$-estradiol and progesterone blood 
values with altered bovine polymorphonuclear leukocyte function. Am. J. Vet. Res. 44:247-253.

Smith, V. G., L. A. Edgerton, H. D. Hafs, and E. M. Convey. 1973. Bovine serum estrogens, progestins and glucocorticoids during late pregnancy, parturition and early lactation. J. Anim. Sci. 36:391-396.

Smith, M. A., N. P. Lucie, M. M. Ferguson, R. J. Mairs, and J. G. Smith. 1986. Progesterone inhibits proliferation of human marrow colony forming cells (CFU-GM) through increased prostaglandin production by marrow macrophages. Br. J. Haematol. 63:649-658.

Smithson, G., K. Medina, I. Ponting, and P. W. Kincade. 1995. Estrogen suppresses stromal cell-dependent lymphopoiesis in culture. J. Immunol. 155:3409-3417.

Thurmond, T. S., F. G. Murante, J. E. Staples, A. E. Silverstone, K. S. Korach, and T. A. Gasiewicz. 2000. Role of estrogen receptor $\alpha$ in hematopoietic stem cell development and B lymphocyte maturation in the male mouse. Endocrinology 141:2309-2318.

Van Bockstaele, D., M. Lenjou, H.-W. Snoeck, F. Lardon, P. Stryckmans, and M. Peetermans. 1993. Direct effects of 13-cis and alltrans retinoic acid on normal bone marrow (BM) progenitors:
Comparative study on $\mathrm{BM}$ mononuclear cells and on isolated CD34+ BM cells. Ann. Hematol. 66:61-66.

Van Merris, V., M. Lenjou, D. Hoeben, G. Nijs, D. Van Bockstaele, and C. Burvenich. 2001a. Culture of bovine bone marrow cells in vitro. Vet. Q. 23:170-175.

Van Merris, V., E. Meyer, F. Gasthuys, and C. Burvenich. 2001b. Sternal aspiration of bone marrow in adult cows. Flem. Vet. J. 70:304-306.

Van Merris, V., E. Meyer, L. Duchateau, J. Blum, and C. Burvenich. 2004. All-trans retinoic acid is increased in the acute-phase related hyporetinemia during Escherichia coli mastitis. J. Dairy Sci. 87:980-987.

Van Werven, T., E. N. Noordhuizen-Stassen, A. J. J. M. Daemen, Y. H. Schukken, A. Brand, and C. Burvenich. 1997. Preinfection in vitro chemotaxis, phagocytosis, oxidative burst, and expression of $\mathrm{CD} 11 \mathrm{~b} / \mathrm{CD} 18$ receptors and their predictive capacity on the outcome of mastitis induced in dairy cows with Escherichia coli. J. Dairy Sci. 80:67-74.

Winters, K. R. H., E. Meyer, V. M. Van Merris, W. L. Van Den Broeck, L. Duchateau, and C. Burvenich. 2003. Sex steroid hormones do not influence the oxidative burst activity of polymorphonuclear leukocytes from ovariectomized cows in vitro. Steroids 68:397406. 